\title{
Selective lobar exclusion by venous clamping during ex vivo lung perfusion
}

Thomas Schweiger, MD, PhD, Alberto Benazzo, MD, Gyoergy Lang, MD, PhD, José Ramon Matilla, MD, and Walter Klepetko, MD, Vienna, Austria

From the Division of Thoracic Surgery, Medical University of Vienna, Vienna, Austria.

T.S. and A.B. contributed equally to this work.

Disclosures: Authors have nothing to disclose with regard to commercial support.

Received for publication Jan 20, 2017; revisions received May 13, 2017; accepted for publication June 7, 2017; available ahead of print Sept 1, 2017.

Address for reprints: Walter Klepetko, MD, Medical University of Vienna, Waehringer Guertel 18-20, 1090

Vienna, Austria (E-mail: walter.klepetko@meduniwien.ac.at).

J Thorac Cardiovasc Surg 2017;154:e87-9

$0022-5223 / \$ 36.00$

Copyright (C) 2017 Published by Elsevier Inc. on behalf of The American Association for Thoracic Surgery http://dx.doi.org/10.1016/j.jtcvs.2017.06.018

$\square$ Video clip is available online.

Donor lungs of a 32-year-old woman $(170 \mathrm{~cm} ; 65 \mathrm{~kg}$; total lung capacity [TLCp], $5.43 \mathrm{~L}$ ), 3 days intubated after nontraumatic ischemic brain damage, were allocated to a high-urgency recipient at our center. The recipient was a 51-year-old woman $(156 \mathrm{~cm} ; 45 \mathrm{~kg}$; TLCp, $4.63 \mathrm{~L}$; real total lung capacity [TLCr], $4.05 \mathrm{~L}$ ) with interstitial pulmonary fibrosis bridged to transplantation with venovenous extracorporeal membrane oxygenation.

Blood gas analysis of the donor after bronchoscopy, opening of the pleura, and recruitment of any atelectasis revealed a partial pressure of oxygen $\left(\mathrm{pO}_{2}\right)$ of $231 \mathrm{~mm}$ $\mathrm{Hg}$ at $100 \%$ fraction of inspired oxygen $\left(\mathrm{FiO}_{2}\right)$. Despite this, the tissue quality of the lungs appeared to be very good (Figure 1, A). Given the lack of explanation for the poor functional status, it was decided

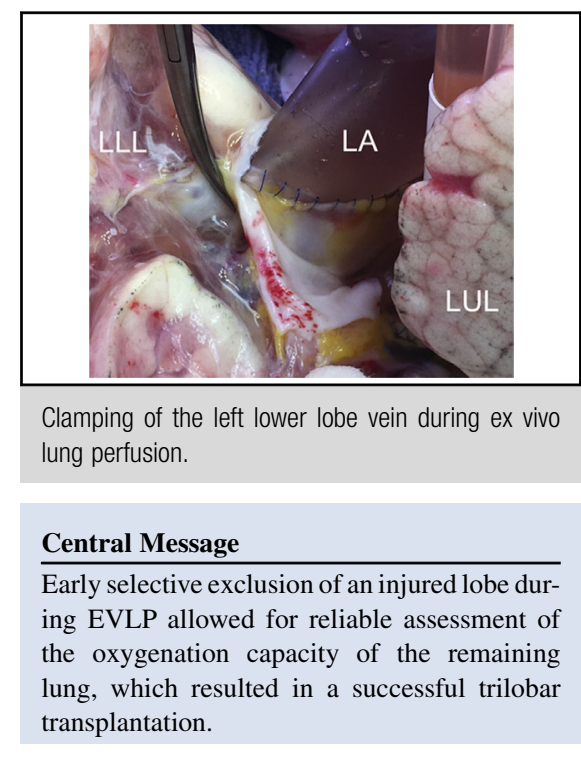

See Editorial Commentaries pages e91 and e93.
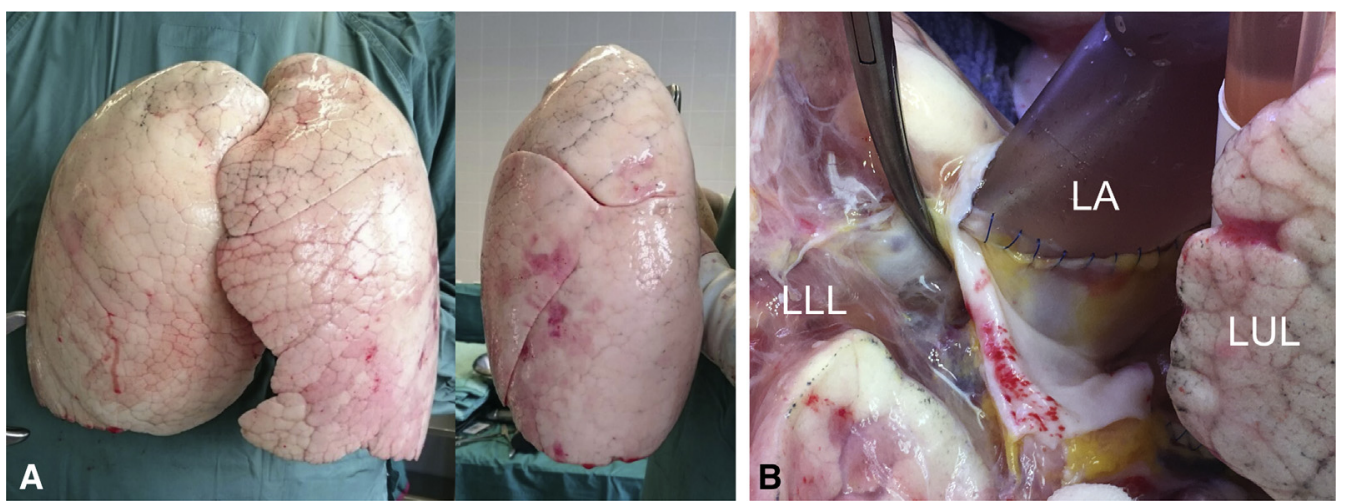

FIGURE 1. A, Donor lungs during ex vivo lung perfusion with macroscopically good tissue quality. B, Clamping of the left lower lobe vein. $L A$, Left atrium; $L L L$, left lower lobe; $L U L$, left upper lobe. 


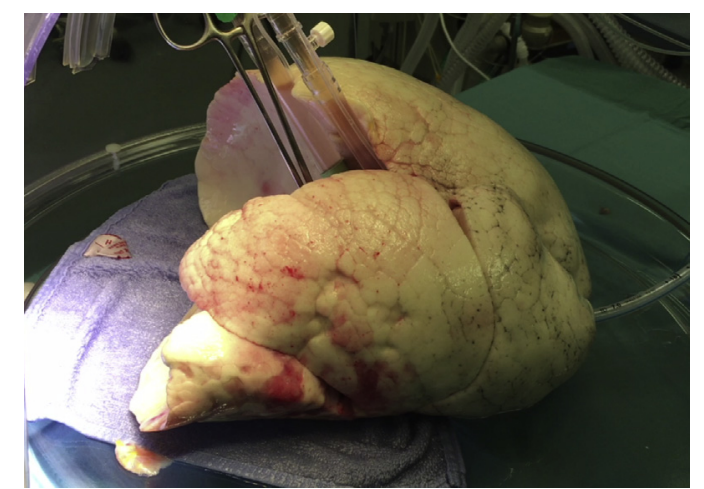

VIDEO 1. Setting of ex vivo lung perfusion with clamp in place. Video available at: http://www.jtcvsonline.org/article/S0022-5223(17) 31197-2/fulltext.

$\Delta \mathrm{pO}_{2}$ was $190 \mathrm{~mm} \mathrm{Hg}$. Moreover, the compliance assessed by disconnecting the tube was reduced in the left lower lobe. Thus, we were confronted with the situation of poor overall performance of the donor lungs during EVLP and impaired tissue quality confined to the left lower lobe. Therefore, the decision was made to exclude the left lower lobe from the EVLP circuit.

The left hilum was prepared, and the lower lobe vein was exposed and clamped (Figure 1, $B$, and Video 1). The perfusion flow was reduced to $80 \%$ of the calculated target flow. Once a stable flow pattern was achieved, blood gas analysis was repeated, revealing a markedly

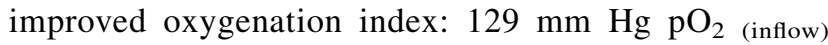

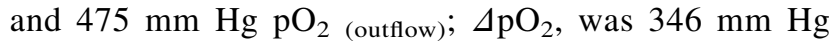
(Table 1). Based on these findings, the lungs were accepted for trilobar transplantation, removed from the EVLP circuit (after 2.5 hours total EVLP time), and stored on ice. On the right side, the middle lobe was removed, and the upper and lower lobes were transplanted. The left lower lobe was removed at the back table and the left upper lobe was transplanted, resulting in a good size match (Figure 2).

Blood gas values on the first postoperative day included $170 \mathrm{~mm} \mathrm{Hg} \mathrm{pO} \mathrm{p}_{2}$ at $60 \% \mathrm{FiO}_{2}$, corresponding to primary graft dysfunction grade 2 (PGD 2). Microbiologic examination of the donor lung revealed growth of Pseudomonas aeruginosa; however, analysis of each subsequent bronchoalveolar lavage during the hospital stay was negative. Histologic examination of the left lower lobe revealed a multifocal, early-stage pneumonia. The patient was finally discharged from the hospital 73 days after transplantation with no graft-related or infectious complications, despite her diminished general condition after a prolonged pretransplantation course in a bridge-to-transplantation setting. At the last follow-up examination at 4 months after transplantation, the patient presented with a good functional outcome (forced expiratory volume in 1 second, $2.05 \mathrm{~L}$ [79\%]; $\mathrm{pO}_{2}$,
TABLE 1. Hemodynamic and respiratory parameters before and after venous clamping

\begin{tabular}{|c|c|c|}
\hline Parameter & Preclamping & Postclamping \\
\hline Pulmonary artery flow, $\mathrm{L} / \mathrm{min}$ & 1.9 & 1.5 \\
\hline $\begin{array}{l}\text { Mean pulmonary artery pressure, } \\
\mathrm{mmHg}\end{array}$ & 10 & 10 \\
\hline Left atrial pressure, $\mathrm{mmHg}$ & 2 & 2 \\
\hline Pulmonary vascular resistance* & 336.8 & 426.7 \\
\hline Mean airway pressure, $\mathrm{cmH}_{2} \mathrm{O}$ & 6 & 6 \\
\hline Peak airway pressure, $\mathrm{cmH}_{2} \mathrm{O}$ & 11 & 11 \\
\hline Plateau airway pressure, $\mathrm{cmH}_{2} \mathrm{O}$ & 11 & 10 \\
\hline $\begin{array}{l}\text { Dynamic compliance, } \mathrm{mL} / \\
\mathrm{cmH}_{2} \mathrm{O}\end{array}$ & 76 & 78 \\
\hline
\end{tabular}

$76 \mathrm{~mm} \mathrm{Hg}$; partial pressure of $\mathrm{CO}_{2}, 40 \mathrm{~mm} \mathrm{Hg}$ ) (Figure 2).

\section{DISCUSSION}

Clamping and exclusion of an injured lobe during EVLP eliminates the shunting volume, which hinders accurate assessment of the oxygenation capacity of the remaining lung. The latter is the main criterion for judging graft performance and organ quality during EVLP. Beyond this, clamping during EVLP might prevent the dissemination of proinflammatory cytokines and bacteria from the injured parenchyma into the EVLP circuit. ${ }^{3}$ Thus, an early decision to clamp the injured lobe as in this case might be protective for the remaining lung tissue. If technically feasible, an exclusion from the arterial supply may be achieved as well. A sufficient fissure and a stable flow pattern during manipulation are prerequisites for this complete isolation from perfusion. Even lobectomy during EVLP might be added after the clamping procedure. $^{4}$

To the best of our knowledge, there is only 1 comparable case report in the literature. Miyoshi and colleagues reported identifying a damaged left lower lobe by separate blood gas analysis from each pulmonary vein. ${ }^{5}$ In our clinical experience, this sampling method often leads to inaccurate measurements. A possible explanation is that following the Toronto protocol, the low flow pattern in the left atrium (left atrial pressure, $3-5 \mathrm{~mm} \mathrm{Hg}$; target flow, $40 \%$ of calculated cardiac output) leads to an unpredictable mixture of perfusate at the orifices of the pulmonary veins. Also in the case report of Miyoshi and colleagues, significantly low $\Delta \mathrm{pO}_{2}$ values $(>200)$ were measured in the macroscopically unaffected lobes.

In conclusion, this clinical case of selective venous clamping during EVLP represents a simple but effective 

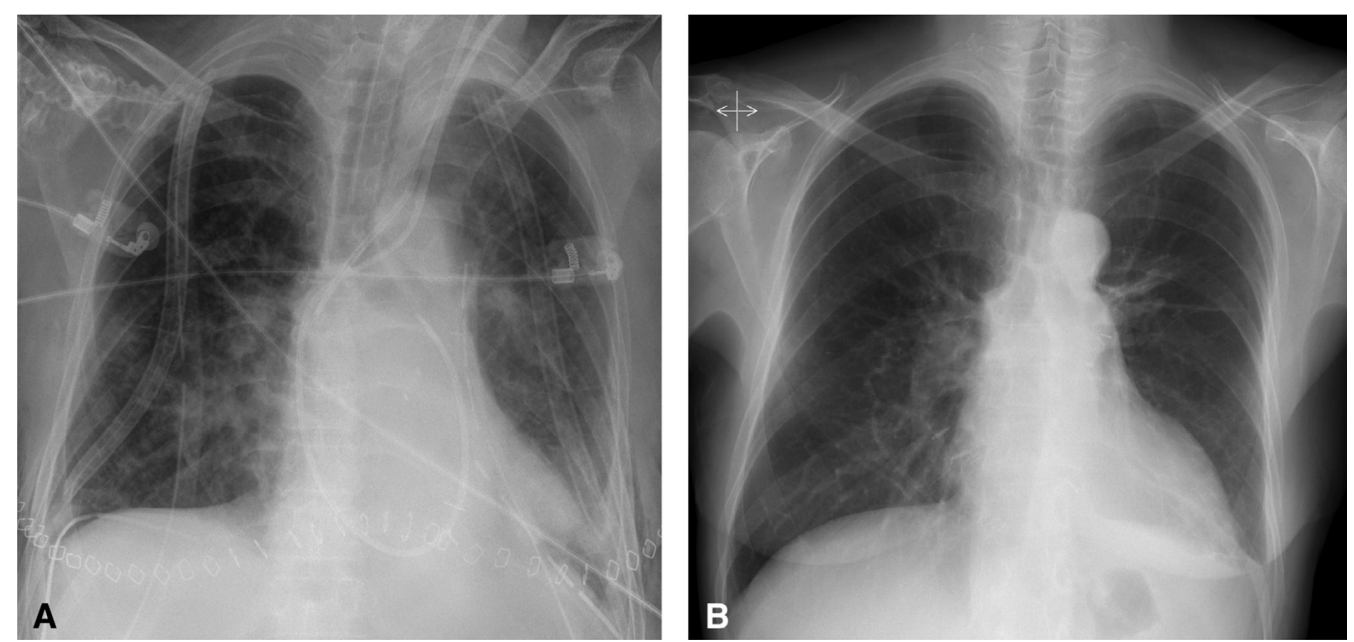

FIGURE 2. Chest X-rays of the recipient after tri-lobar transplantation (A) on the first post-operative day (PGD grade 2) and (B) at the last follow-up examination four months after transplantation.

method of increasing the use of donor lungs deemed unacceptable after standard EVLP.

\section{References}

1. Aigner C, Slama A, Hotzenecker K, Scheed A, Urbanek B, Schmid W, et al. Clinical ex vivo lung perfusion: pushing the limits. Am J Transplant. 2012;12:1839-47.

2. Cypel M, Yeung JC, Machuca T, Chen M, Singer LG, Yasufuku K, et al. Experience with the first 50 ex vivo lung perfusions in clinical transplantation. J Thorac Cardiovasc Surg. 2012;144:1200-6.
3. Nakajima D, Cypel M, Bonato R, Machuca TN, Iskender I, Hashimoto K, et al. Ex vivo perfusion treatment of infection in human donor lungs. Am J Transplant. 2016;16:1229-37.

4. Nosotti M, Rosso L, Mendogni P, Tosi D, Palleschi A, Righi I, et al. Graft downsizing during ex vivo lung perfusion: case report and technical notes. Transplant Proc. 2014;46:2354-6.

5. Miyoshi K, Oto T, Konishi Y, Hirano Y, Okada M, Iga N, et al. Use of extended-criteria lungs on a lobe-by-lobe basis through ex vivo lung perfusion assessment. Ann Thorac Surg. 2015;99:1819-21. 